\title{
Morinda citrifolia L. (noni) improves the Quality of Life in adults with Osteoarthritis
}

\section{${ }^{1}$ Mian-Ying Wang, ${ }^{3}$ M. Nawal Lutfiyya, ${ }^{2}$ Vicki Weidenbacher-Hoper, ${ }^{1}$ Lin Peng, ${ }^{2}$ Martin S. Lipsky, and ${ }^{1}$ Gary Anderson}

${ }^{1}$ Department of Pathology and ${ }^{2}$ Department of Family and Community Medicine, University of Illinois College of Medicine at Rockford, 1601 Parkview Avenue, Rockford, IL 61107, USA. ${ }^{3}$ Essentia Institute of Rural Health, 502 East 2nd Street, Duluth, MN 55805, USA

Running title: Noni improves the QoL of adults with osteoarthritis

Corresponding Author: Mian-Ying Wang, MD,

Department of Pathology,

University of Illinois College of Medicine at Rockford

1601 Parkview Ave, Rockford, IL 61107, USA

Submission date: 24 January 2011, Acceptance date: 20 February 2011, Publication date: 20 February 2011

\section{$\underline{\text { Abstract }}$}

Background: Morinda citrifolia Linn (noni), as a "pain killer", has been used as a traditional medicine by Polynesians for over 2000 years. It was reported to have a broad range of therapeutic effects including analgesic and anti-inflammation. The in-vitro and in vivo antiinflammatory and analgesic properties of noni juice (NJ) suggest that $\mathrm{NJ}$ may be a useful adjunctive treatment for osteoarthritis (OA). In this pilot study we explored whether NJ improves the symptoms and Quality of Life (QoL) for adults with OA. We also sought to evaluate the tolerability and safety of $\mathrm{NJ}$ for patients with OA in a primary care setting.

Methods: This was an open label three-month intervention pilot study. Data were collected by pre/post intervention survey and laboratory testing. Inclusion criteria were: adults of both sexes aged 40 to 75, with a diagnosis of OA on the hip or knee by x-ray examination provided by their primary care physician, not on prescription medicine for OA, and who were willing to drink $3 \mathrm{oz}$ of $\mathrm{NJ}$ a day for 90 days. 
Results: Of the 64 questions measuring different aspects of QoL asked on the pre/post survey, $49(77 \%)$ had significant pre/post mean scale differences as measured by independent $t$-test. The OA patients reported being significantly more satisfied with their current health conditions including mobility, walking and bending, hand, finger, and arm functions, household tasks, social activity, arthritis pain, work ability, level of tension, and mood. The study participants were also more positive about their future health and reported taking less over-the-counter (OTC) pain relievers. Pre/post laboratory testing including: lipid panel, liver and kidney functions were in the normal ranges. High Sensitive C Reactive Protein (hsCRP), an inflammatory biomarker, was reduced by $10 \%$ after the intervention.

Conclusion: As a nutritional supplement, NJ demonstrated a potential therapeutic effect and improved the symptoms and the QoL for adults with OA. A larger, double blinded, and placebo controlled clinical trial study is needed to confirm these benefits. NJ has the potential to become an adjunctive therapy for OA patients.

\section{Clinical trial registration number: NCT01070264.}

Key words: $\quad$ Morinda citrifolia (noni), Noni juice (NJ), Osteoarthritis, Quality of life (QoL), pain scales

\section{Background}

Approximately $10 \%$ of people in the U.S. have OA, making it the most common form of arthritis and one of the most prevalent chronic diseases in western countries. For people older than 75 the estimated prevalence of OA rises to between 70 - 90\% [1].

While the etiology of $\mathrm{OA}$ is multi-factorial, the condition results from the gradual degeneration of joint cartilage. Joint cartilage normally cushions the bones in a joint and if damaged causes bone overgrowth and fragmentation of the cartilage which can lead to inflammation, pain and functional impairment. As a result it is not surprising that OA is a leading cause of disability and that between 10 to $30 \%$ of those affected with OA suffer from significant pain and disability [2-6].

Disease modifying treatments that halt the progression of OA remain elusive and as a result current management focuses on reducing symptoms [7]. These include interventions such as weight loss, exercise, analgesics, steroid joint injections, joint replacement and medications [8]. Non-steroid anti-inflammatory drugs [NSAIDs] are one type of medication though widely used for symptoms, have a significant side effect profile that compromises their benefits. While selective cyclooxygenase (Cox-2) inhibitors provide symptom relief with reduced GI side effects, an associated increase in the risk of cardiovascular disease led to several of these drugs being withdrawn from the market [9]. Due to a favorable safety profile many consider 
acetaminophen as drug of choice for OA; however, acetaminophen predominately affects pain and may have only a modest benefit on improving function and relieving stiffness [10]. Faced with these challenges, many patients and health providers turn to alternative methods [11]. One viable alternative may be the complementary therapy of NJ made from Morinda citrifolia (noni) fruits [12].

Several research studies support the rationale for the traditional use of $\mathrm{NJ}$ for treating inflammatory and analgesic disorders [11, 13]. For decades, Polynesians have used noni for pain and to reduce inflammation [14]. The specie Morinda citrifolia L. [noni] belongs to the genus Morinda and the family Rubiaceae. Morinda includes about 80 species, of which noni is considered the "queen" [15]. Studies examining noni reported that the noni fruit possesses analgesic and tranquilizing activities [16]. An alcohol extract of noni fruit puree showed an analgesic and anti-inflammatory effect by inhibiting MMP-9 release from human monocytes after stimulation with lipopolysaccharides (LPS) and this effect was comparable to hydrocortisone. The authors claimed that preparations of noni fruits are effective in decreasing pain and joint destruction caused by arthritis (17). Younis and his colleagues tested the analgesic and sedative effects of noni extract and found "a significant, dose-related, central analgesic activity in mice" and that "the analgesic efficacy of the noni extract was about $75 \%$ as strong as morphine, yet non-addictive and side effect free [18]". Research comparing the analgesic effect of NJ to aspirin using hot-plate and twist assays in mice also supports $\mathrm{NJ}$ as a potentially effective treatment for OA [19].

Additionally, an anti-inflammatory effect of NJ was observed in acute liver injury models induced by $\mathrm{CCl}_{4}$ in female SD rats [20]. Other research revealed anti-oxidative activity that scavenges reactive oxygen species (ROS) and quenches lipid peroxides (LPO) in smokers [21]. Of particular interest in terms of NJ's potential as a therapeutic natural product for OA, is the finding the $\mathrm{NJ}$ is a partial Cox-2 inhibitor in vitro with an inhibitory effect about $40 \%$ of the effect of celexcoxib [22].

These research findings coupled with its traditional use as a treatment for pain suggest that NJ might be an effective therapeutic nutritional supplement for OA patients. The goal of this study was to conduct a preliminary exploration of NJ's impact on the symptoms and QoL of OA patients and at the same time to examine its tolerability and safety as a complimentary therapeutic nutritional agent for OA.

\section{Methods and Materials}

This study was a 12-week open label pilot intervention study for individuals with OA to explore the potential benefit of NJ for symptoms associated with OA. Research participants were recruited consecutively and enrolled into the study until a targeted sample size of approximately 100 was reached. Pre/post intervention assessment was used to examine efficacy. The inclusion criteria entailed: adults aged 40 to 75 of both sexes with X-ray diagnosis of OA of the hip or knee who were not taking prescription medicine for arthritis and were willing to drink $3 \mathrm{oz}$ of NJ 
daily for 90 days. The diagnostic criteria were deliberately set to mimic the real life clinical setting in which NJ would most likely be used---a primary care physician diagnosis of OA for those experiencing symptoms of OA proved by x-ray examination. Adults appearing to meet the study's eligibility criteria were interviewed by an experienced clinical coordinator to confirm eligibility and to ensure that potential study participants were willing to complete all of the study measures including blood draws. Informed consent was obtained from the participants once it was ascertained that they met the enrollment criteria and were willing to participate.

To help ensure the intake of a daily dose of $3 \mathrm{oz}$ of NJ, all enrolled study participants were asked to drink $1 \mathrm{oz}$ in the morning before breakfast, $1 \mathrm{oz}$ before lunch, and $1 \mathrm{oz}$ before bedtime. Study participants picked up their one-month supply of NJ at the time of enrollment, and again at the end of the first and then second month of the intervention. A $20 \mathrm{ml}$ blood sample for laboratory testing was drawn at enrollment and at the last visit. To confirm compliance with the treatment protocol, the remaining NJ from the previous month's supply was measured and recorded. At the time of follow up, the study coordinator asked the study participants if they were experiencing any new problems or symptoms that precluded their receiving the next $\mathrm{NJ}$ allotment.

The clinical coordinator attempted to contact by phone anyone who failed to show up for a follow up appointment. If a research participant failed to respond after 3 contacts or more than 30 days or missed 3 scheduled appointments they were dropped from the study. The NJ used in this study was Tahitian Noni ${ }^{\circledR}$ juice donated by Morinda Holding Inc. The study was approved by the University of Illinois-Chicago, College of Medicine at Rockford's Institutional Review Board.

At enrollment as baseline and then again at the end of the last visit, two validated instruments were used to collect pre/post intervention study data on self-reported pain from QoL associated with OA. The Arthritis Impact Measurement Scales [AIMS 2] were used to measure self-reported pain in the study participants [23]. The Short Form-36 Version 2 [SF-36 V2] form was used for the evaluation of QoL [24]. Both the AIMS 2 and the SF-36 V2 are validated instruments [25]. Reliability and validity of the AIMS 2 have been well documented in arthritis patients. The SF-36 V2 is both a multipurpose survey of general health status as well as a QoL measure.

Some modifications, however, were made to the instruments. Due to the overlap of some items on the AIMS 2 and the SF-36 V2, we combined the two forms into one questionnaire. The AIMS 2 questionnaire includes 78 items used to establish severity of an individual's clinical status; these were included in the combined questionnaire. This instrument also contains subscales for pain, stiffness, and function. The SF-36 questionnaire consists of several selfefficacy questions used to assess QoL. The QoL questions asked study participants to appraise their current level of function and satisfaction, compared to what they perceive to be their ideal. This assessment also asked study participants to express their ability to perform daily activities 
across multiple domains including: physical, social, cognitive functioning role activities, and emotional well-being.

In addition to the two validated measures, another questionnaire was used to collect data on patient characteristics such as age, gender, race, social status, and height and weight to calculate body mass index [BMI], disease related characteristics [location of symptoms, duration of symptoms, family history] and co-morbidities. Of these, BMI and co-morbidities were monitored throughout the intervention study.

\section{Statistical analysis}

A power analysis was calculated for a two-tailed test of significance using a $t$-test for a medium effect size, alpha was set at $<0.05$ and beta at .80 . This analysis yielded that a sample size of 70 would be sufficient to detect possible significant differences pre/post intervention and a decision was made to recruit approximately 100 study participants to assure a minimum of 70 subjects when accounting for possible attrition.

Several statistical tests were used to determine if the NJ intervention yielded a significant impact on the self-reported QoL measures for each study participant. Basic $t$-test analysis was performed [26-27] with the differences in the primary outcomes [pain and function] measured before and after the intervention study based on the intention to treat. The safety of NJ was evaluated based on the compliance of the study participants and laboratory test performed on the blood samples.

\section{Results}

One hundred and one adults with OA enrolled in the study and 82 [81\%] completed the intervention study. While several of those completing the intervention study complained about the unpleasant taste of $\mathrm{NJ}$, no one reported a side effect that precluded them from completing the intervention study. Of the 19 who did not complete the intervention study, one moved from the area, one was hospitalized for reasons unrelated to $\mathrm{NJ}$ and one was dropped from the intervention study because she reported to the study coordinator that her primary care physician detected asymptomatic hyperkalemia on a routine blood test. The remaining original study participants either did not respond to multiple attempts to reach them or they rescheduled appointments but failed to appear.

Table 1 displays the demographic characteristics of the study participants who completed the intervention study. Almost 75\% [74.4\%] of the participants completing the intervention study were female, half [50.0\%] were obese [BMI > 30], 32.9\% were overweight, and the vast majority [93.9\%] were Caucasian. A little over half of the completing intervention study participants were partnered [59.0\%], 62.2\% did not graduate from college and 61.2\% lived in households with incomes $\geq \$ 40,000$. Those who did not complete the study did not differ significantly from the study group who finished the intervention study. 
Table 1. Demographic characteristic of study participants completing the 3-month trial

\begin{tabular}{llcc}
\hline \multirow{3}{*}{ Gender } & \multicolumn{1}{c}{ Variables } & $\mathrm{n}$ & $\%$ \\
& Female & 21 & 25.6 \\
\multirow{3}{*}{ BMI } & Normal & 61 & 74.4 \\
& Overweight & & 17.1 \\
& Obese & 14 & 32.9 \\
& & 27 & 50.0 \\
Race & Caucasian & 41 & 93.9 \\
& African American & & 6.1 \\
Marital Status & Partnered & 77 & 59.0 \\
& Not Partnered & 5 & 41.0 \\
Years of Formal & $<$ College Education & 49 & 62.2 \\
Education & College Graduate & 34 & 37.8 \\
Household Income & $<\$ 40,000$ & 51 & 38.8 \\
& $\geq \$ 40,000$ & 31 & 61.2 \\
\hline Note: Age 62.1 \pm 8.1 [mean \pm SD]. Classification of BMI: normal [BMI < 24.9], over weight [BMI=25.0 to 29.9, \\
obese [BMI=30.0 or higher].
\end{tabular}

Of the 64 questions related to QoL, 49 [77\%] had significant pre/post differences in the mean as measured by an independent $t$-test. All the differences that achieved statistical significance favored post intervention study improvement on the QoL measures. Table 2 summarizes the significant pre/post changes in the QoL measures for the body movement and function measures. All of the movement and function questions were asked in terms of the past month.

Table 3 displays the significant pre/post changes in the QoL measures for study participants on the duration and severity of arthritis pain, psychological state measures of tension and mood and satisfaction with QoL on multiple dimensions. All questions were asked in terms of the past month. The results indicated that both the duration and the severity of pain were reduced post intervention study and after the consumption of NJ over a three month time frame. Regarding the psychological state measures of tension and mood the results also revealed that both the level of tension experienced by OA patients participating in this intervention study as well as the mood of the study participants improved. The results measuring the significant pre/post differences in level of satisfaction on multiple dimensions indicated that there were statistically significant pre/post positive differences in OA patient satisfaction with mobility, walking and bending, hand and finger functions, arm function, self-care, household tasks, social activity, arthritis pain, work, level of tension, and mood. 
The impact that the study participant's OA had on multiple dimensions was also assessed pre/post during the NJ clinical intervention study. The question was posed in terms of: How much of your problem in each area of health was due to your arthritis? The significant results are displayed in Table 4. For the dimensions of walking and bending, arthritis pain, work, level of tension, and mood the impact of OA was significantly lessened.

\begin{tabular}{|c|c|c|c|c|}
\hline \multicolumn{2}{|c|}{ These questions were asked in terms of the past month. } & \multirow{2}{*}{$\begin{array}{c}\begin{array}{c}\text { Pre-trial } \\
{[\text { mean } \pm \mathrm{SD}]}\end{array} \\
4.35 \pm 0.78\end{array}$} & \multirow{2}{*}{$\begin{array}{c}\begin{array}{c}\text { Post-trial } \\
{[\text { mean } \pm \text { SD }]}\end{array} \\
4.56 \pm 0.74\end{array}$} & \multirow{2}{*}{$\begin{aligned} & p \\
& <0.05\end{aligned}$} \\
\hline \multirow{4}{*}{$\begin{array}{l}\text { Mobility level } \\
\text { Scale } 1 \text { [no days]-5 [all } \\
\text { days] }\end{array}$} & $\begin{array}{l}\text { How often were you out of the house for at } \\
\text { least part of the day? }\end{array}$ & & & \\
\hline & $\begin{array}{l}\text { How often were you able to do errands in } \\
\text { the neighborhood? }\end{array}$ & $4.41 \pm 0.93$ & $4.55 \pm 0.87$ & $<0.05$ \\
\hline & $\begin{array}{l}\text { How often did someone have to assist you } \\
\text { to get around outside your home? }\end{array}$ & $1.41 \pm 0.89$ & $1.13 \pm 0.44$ & $<0.05$ \\
\hline & $\begin{array}{l}\text { How often were you in bed or chair for } \\
\text { most or all of the day? }\end{array}$ & $1.54 \pm 1.00$ & $1.33 \pm .074$ & $<0.05$ \\
\hline \multirow[t]{4}{*}{$\begin{array}{l}\text { Walking and bending } \\
\text { Scale } 1 \text { [no days]-5 [all } \\
\text { days] }\end{array}$} & $\begin{array}{l}\text { Did you have trouble doing vigorous } \\
\text { activities such as running, lifting heavy } \\
\text { objects, or participating in strenuous sports? }\end{array}$ & $4.43 \pm 1.04$ & $3.84 \pm 1.39$ & $<0.01$ \\
\hline & $\begin{array}{l}\text { Did you have trouble either walking several } \\
\text { blocks or climbing a few flights of stairs? }\end{array}$ & $3.66 \pm 1.42$ & $2.79 \pm 1.43$ & $<0.05$ \\
\hline & $\begin{array}{l}\text { Did you have trouble bending, lifting or } \\
\text { stooping? }\end{array}$ & $3.41 \pm 1.41$ & $2.73 \pm 1.35$ & $<0.01$ \\
\hline & $\begin{array}{l}\text { Did you have trouble either walking one } \\
\text { block or climbing one flight of stairs? }\end{array}$ & $2.98 \pm 1.62$ & $2.21 \pm 1.44$ & $<0.05$ \\
\hline \multirow{3}{*}{$\begin{array}{l}\text { Arm function } \\
\text { Scale } 1 \text { [no days]-5 [all } \\
\text { days] }\end{array}$} & Could you easily put on a pullover sweater? & $4.73 \pm 0.69$ & $4.84 \pm 0.46$ & $<0.05$ \\
\hline & Could you easily comb or brush your hair? & $4.74 \pm 0.73$ & $4.90 \pm 0.29$ & $<0.05$ \\
\hline & $\begin{array}{l}\text { Could you easily reach shelves that were } \\
\text { above your head? }\end{array}$ & $4.21 \pm 1.10$ & $4.52 \pm 0.82$ & $<0.05$ \\
\hline \multirow{2}{*}{$\begin{array}{l}\text { Self-care tasks } \\
\text { Scale 1[never]-5[always] }\end{array}$} & Did you need help with a bath or shower? & $1.27 \pm 0.71$ & $1.12 \pm 0.55$ & $<0.01$ \\
\hline & Did you need help to get dressed? & $1.21 \pm 0.58$ & $1.06 \pm 0.28$ & 0.000 \\
\hline $\begin{array}{l}\text { Household tasks } \\
\text { Scale 1[never]-5[always] }\end{array}$ & $\begin{array}{l}\text { If you had the necessary transportation, } \\
\text { could you go shopping for groceries } \\
\text { without help }\end{array}$ & $4.76 \pm 0.63$ & $4.89 \pm 0.38$ & $<0.01$ \\
\hline $\begin{array}{l}\text { Support from Friends } \\
\text { and Family } \\
\text { Scale } 1 \text { [never]-5[always] }\end{array}$ & $\begin{array}{l}\text { Did you feel that your family or friends } \\
\text { understood the effects of your arthritis? }\end{array}$ & $3.50 \pm 1.03$ & $3.78 \pm 1.12$ & $<0.05$ \\
\hline
\end{tabular}


Table 3. Pre/post assessment of arthritis pain, psychological state and satisfaction measures

\begin{tabular}{|c|c|c|c|c|}
\hline \multicolumn{2}{|c|}{$\begin{array}{l}\text { All questions were asked in terms of the past month. } \\
\text { Pain measures }\end{array}$} & \multirow{2}{*}{$\begin{array}{c}\begin{array}{c}\text { Pre-trial } \\
{[\text { mean } \pm \mathrm{SD}]}\end{array} \\
3.37 \pm 1.17\end{array}$} & \multirow{2}{*}{$\begin{array}{c}\begin{array}{c}\text { Post-trial } \\
{[\text { mean } \pm \mathrm{SD}]}\end{array} \\
2.57 \pm 1.13\end{array}$} & \multirow{2}{*}{$\begin{array}{r}\quad p \\
<0.05\end{array}$} \\
\hline \multirow{4}{*}{$\begin{array}{l}\text { Duration of } \\
\text { arthritis pain Scale } \\
1 \text { [no days] - } 5 \text { [all } \\
\text { days] }\end{array}$} & $\begin{array}{l}\text { How often did you have severe pain from your } \\
\text { arthritis? }\end{array}$ & & & \\
\hline & $\begin{array}{l}\text { How often did you have pain in two or more joints } \\
\text { at the same time? }\end{array}$ & $3.61 \pm 1.23$ & $3.09 \pm 1.14$ & $<0.05$ \\
\hline & $\begin{array}{l}\text { How often did your morning stiffness last more } \\
\text { than one hour from the time you woke up? }\end{array}$ & $3.16 \pm 1.28$ & $2.34 \pm 1.23$ & $<0.05$ \\
\hline & $\begin{array}{l}\text { How often did your pain make it difficult for you to } \\
\text { sleep? }\end{array}$ & $2.95 \pm 1.20$ & $2.32 \pm 1.05$ & $<0.05$ \\
\hline $\begin{array}{l}\text { Severity of arthritis } \\
\text { pain Scale } 1 \\
\text { [none] - } 5 \text { [severe] }\end{array}$ & $\begin{array}{l}\text { How would you describe the arthritis pain you } \\
\text { usually had? }\end{array}$ & $4.01 \pm 0.73$ & $3.67 \pm 0.83$ & $<0.05$ \\
\hline \multicolumn{5}{|c|}{ Psychological state measures scale 1 [never] - 5 [always] } \\
\hline \multirow[t]{4}{*}{ Level of tension } & How often have you felt tense or high strung? & $2.96 \pm 1.01$ & $2.51 \pm 0.85$ & $<0.01$ \\
\hline & $\begin{array}{l}\text { How often have you been bothered by nervousness } \\
\text { or your nerves? }\end{array}$ & $2.72 \pm 0.97$ & $2.29 \pm 0.85$ & $<0.01$ \\
\hline & $\begin{array}{l}\text { How often have you felt relaxed and free of } \\
\text { tension? }\end{array}$ & $3.37 \pm 0.83$ & $3.61 \pm 0.74$ & $<0.01$ \\
\hline & How often have you felt calm and peaceful? & $3.35 \pm 0.79$ & $3.66 \pm 0.77$ & $<0.01$ \\
\hline \multirow[t]{5}{*}{ Mood } & How often have you enjoyed the things you do? & $3.82 \pm 0.79$ & $4.04 \pm 0.69$ & $<0.01$ \\
\hline & $\begin{array}{l}\text { How often have you been in low or very low } \\
\text { spirits? }\end{array}$ & $2.63 \pm 0.81$ & $2.21 \pm 0.78$ & $<0.01$ \\
\hline & $\begin{array}{l}\text { How often did you feel that nothing turned out the } \\
\text { way you wanted it to? }\end{array}$ & $2.62 \pm 0.88$ & $2.21 \pm 0.85$ & $<0.01$ \\
\hline & $\begin{array}{l}\text { How often did you feel that others would be better } \\
\text { off if you were dead? }\end{array}$ & $1.43 \pm 0.82$ & $1.28 \pm 0.71$ & $<0.01$ \\
\hline & $\begin{array}{l}\text { How often did you feel so down in the dumps that } \\
\text { nothing would cheer you up? }\end{array}$ & $1.72 \pm 0.92$ & $1.41 \pm 0.70$ & $<0.01$ \\
\hline \multicolumn{5}{|c|}{ Satisfaction measures scale 1[very dissatisfied] - 5 [very satisfied] } \\
\hline \multicolumn{2}{|c|}{ Mobility level [example: do errands] } & $3.14 \pm 1.48$ & $3.93 \pm 1.22$ & 0.000 \\
\hline \multicolumn{2}{|c|}{ Walking and bending [example: climb stairs] } & $2.33 \pm 1.28$ & $3.37 \pm 1.33$ & 0.000 \\
\hline \multicolumn{2}{|c|}{ Hand and finger function [example: tie a bow] } & $3.88 \pm 1.26$ & $4.43 \pm 0.93$ & $<0.01$ \\
\hline \multicolumn{2}{|c|}{ Arm function [example: comb hair] } & $4.21 \pm 1.17$ & $4.45 \pm 0.94$ & $<0.05$ \\
\hline \multicolumn{2}{|c|}{ Household tasks [example: housework] } & $3.52 \pm 1.35$ & $4.11 \pm 1.12$ & $<0.05$ \\
\hline \multicolumn{2}{|c|}{ Social activity [example: visit friends] } & $4.08 \pm 1.24$ & $4.34 \pm 1.11$ & 0.000 \\
\hline \multicolumn{2}{|c|}{ Arthritis pain [example: joint pain] } & $2.11 \pm 1.15$ & $3.14 \pm 1.23$ & 0.000 \\
\hline \multicolumn{2}{|c|}{ Work [example: reduced hours] } & $3.41 \pm 1.32$ & $4.18 \pm 1.15$ & 0.000 \\
\hline \multicolumn{2}{|c|}{ Level of tension [example: felt tense] } & $3.26 \pm 1.27$ & $4.02 \pm 1.05$ & 0.000 \\
\hline \multicolumn{2}{|c|}{ Mood [example: down in the dumps] } & $3.63 \pm 1.12$ & $4.13 \pm 1.03$ & 0.000 \\
\hline
\end{tabular}




\begin{tabular}{|c|c|c|c|}
\hline $\begin{array}{l}\text { How much of your problem in each area of health was due to your } \\
\text { arthritis? This question was asked in terms of the past month. } \\
\text { Scale } 1 \text { [due entirely to my arthritis] - } 6 \text { [not a problem for me] }\end{array}$ & $\begin{array}{c}\text { Pre-trial } \\
{[\text { mean } \pm \mathrm{SD}]}\end{array}$ & $\begin{array}{l}\text { Post-trial } \\
{[\text { mean } \pm} \\
\text { SD] }\end{array}$ & $p$ \\
\hline Walking And Bending [example: climb stairs] & $2.38 \pm 1.35$ & $2.78 \pm 1.53$ & $<0.05$ \\
\hline Arthritis Pain [example: joint pain] & $1.95 \pm 1.02$ & $2.50 \pm 1.37$ & 0.000 \\
\hline Work [example: reduced hours] & $3.98 \pm 1.82$ & $4.69 \pm 1.67$ & 0.000 \\
\hline Level of tension [example: felt tense] & $4.11 \pm 1.58$ & $4.73 \pm 1.45$ & $<0.01$ \\
\hline Mood [example: down in the dumps] & $4.38 \pm 1.59$ & $4.96 \pm 1.39$ & $<0.05$ \\
\hline
\end{tabular}

Table 5 presents data on study participants' pre/post assessments of their current and future health. Study participants indicated that they felt more positive about their current and future health after the 3-month NJ intervention study. Study participants reported that satisfaction with health improved, the degree to which health problems were attributed to OA lessened, an assessment of self health in comparison to peer's improved and the frequency to taking medication for OA decreased post intervention study.

\begin{tabular}{|c|c|c|c|}
\hline & $\begin{array}{c}\text { Pre-trial } \\
{[\text { mean } \pm \mathrm{SD}]}\end{array}$ & $\begin{array}{l}\text { Post-trial } \\
{[\text { mean } \pm} \\
\text { SD] }\end{array}$ & $p$ \\
\hline $\begin{array}{l}\text { How satisfied are you with your health now? Scale } 1 \text { [very } \\
\text { dissatisfied]-5 [very satisfied] }\end{array}$ & $2.95 \pm 1.25$ & $3.50 \pm 1.17$ & 0.000 \\
\hline $\begin{array}{l}\text { How much of your problem with your health now is due to your } \\
\text { arthritis? Scale } 1 \text { [due entirely to my arthritis] - } 6 \text { [not a problem for } \\
\text { me] }\end{array}$ & $2.57 \pm .94$ & $2.89 \pm 1.04$ & $<0.05$ \\
\hline $\begin{array}{l}\text { Considering all the ways that your arthritis affects you, how well are } \\
\text { you doing compared to other people your age? Scale } 1 \text { [very poorly] } \\
-5 \text { [very well] }\end{array}$ & $3.36 \pm 1.10$ & $3.80 \pm 1.01$ & 0.000 \\
\hline $\begin{array}{l}\text { How often have you had to take medication for your arthritis? Scale } 1 \\
\text { [no days]-5 [all days] }\end{array}$ & $3.53 \pm 1.62$ & $3.16 \pm 1.65$ & $<0.001$ \\
\hline
\end{tabular}

Patients were also assessed by pre/post intervention study laboratory tests [see Table 6]. With the exception of a very modest increase in creatinine levels, all other markers tested remained unchanged 


\begin{tabular}{|l|c|c|c|c|}
\hline \multicolumn{2}{|l|}{ Table 6. Pre/post laboratory results } \\
\hline \multirow{4}{*}{ Kidney function } & $\begin{array}{c}\text { Pre-trial } \\
{[\text { mean } \pm \text { SD }]}\end{array}$ & $\begin{array}{c}\text { Post-trial } \\
{[\text { mean } \pm \text { SD }]}\end{array}$ & $p$ \\
\cline { 2 - 5 } & Urea nitrogen & $15.4 \pm 4.1$ & $14.8 \pm 5.5$ & $>0.05$ \\
\cline { 2 - 5 } & Creatinine & $0.91 \pm 0.16 *$ & $0.97 \pm 0.19$ & $<0.05$ \\
\hline Liver function & BUN/Creatinine ratio & $16.9 \pm 25.6$ & $15.3 \pm 5.7$ & $>0.05$ \\
\cline { 2 - 5 } & Total protein & $7.1 \pm 1.6$ & $6.9 \pm 0.4$ & $>0.05$ \\
\cline { 2 - 5 } & Albumin & $4.0 \pm 0.33$ & $4.0 \pm 0.4$ & $>0.05$ \\
\cline { 2 - 5 } & Bilirubin total & $0.82 \pm 0.51$ & $0.77 \pm 0.26$ & $<0.05$ \\
\cline { 2 - 5 } & Bilirubin direct & $0.14 \pm 0.1$ & $0.12 \pm 0.06$ & $>0.05$ \\
\cline { 2 - 5 } & ALP & $74.2 \pm 30.0$ & $73.5 \pm 29.3$ & $>0.05$ \\
\cline { 2 - 5 } & AST & $26.9 \pm 11.7$ & $26.1 \pm 11.0$ & $>0.05$ \\
\hline Lipoprotein profile & ALT & $191.9 \pm 35.5$ & $197.9 \pm 34.0$ & $>0.05$ \\
\cline { 2 - 5 } & Total cholesterol & $120.1 \pm 71.6$ & $121.8 \pm 80.9$ & $>0.05$ \\
\hline \multirow{2}{*}{$\begin{array}{l}\text { Inflammatory } \\
\text { marker }\end{array}$} & Triglyceride & $4.9 \pm 4.99$ & $4.2 \pm 3.6$ & $>0.05$ \\
\hline Plasma & Hs-C-reactive protein & $67.08+/-27.4$ & $66.21+/-24.5$ & $>0.05$ \\
\hline
\end{tabular}

\section{Discussion}

No ideal agent exists for the treatment of OA and while a number of OTC and prescription medications are available, many patients turn to nutraceuticals for managing their OA. In a 2009 study, over $40 \%$ of those surveyed used an alternative OA treatment [28]. Despite their wide use, many in the scientific community remain skeptical about alternative agents since there is often little evidence to support their use. The study reported on here explored if NJ, one type of widely used nutraceutical, improved the symptoms and QoL of adults with a diagnosis OA. The findings of this 12-week pilot study intervention suggested that $\mathrm{NJ}$ may be an effective treatment for OA. Our results revealed that study group scores improved in multiple dimensions including pain symptoms, QoL measures, functional activity and psychological well being. An added benefit was that research participants reported taking other supplemental OTC medications for OA less frequently.

The improvement in pain scores and function found in this pilot study was not surprising given that NJ has demonstrated effectiveness in both lab and animal models as a dual Cox-1 and Cox-2 inhibitor and pain reliever. More interesting were the concomitant improvements in QoL, psychological well being, satisfaction with personal health, and having a more positive outlook on life. While this may be a secondary result of reduced pain symptoms and improved function, a wide range of in vitro studies up-to-date indicate that $\mathrm{NJ}$ has biological activity that might yield additional clinical benefit beyond its ability to relieve pain and improve function. These include findings that demonstrate antioxidant activity [29], antimicrobial activity [30], xanthene oxidase inhibition [31], and an inhibitory effect on lipoprotein lipase activity [32]. Recently Deng and 
colleagues demonstrated significant binding affinity of noni extract to the gamma-aminobutyric acid A [GABAa] inhibitory neurotransmitter receptor which provides a possible biological mechanism for the stress reducing benefits seen in this intervention study [22]. However, while these and other studies demonstrate a biologic rationale for NJ, the importance of this pilot study is that it is one of the few human studies that provide evidence of NJ's potential benefit in a clinical setting [33].

In addition to evaluating NJ's benefits as a nutraceutical, this pilot study sought to evaluate its tolerability and safety. In general, previous reports have indicated that NJ is safe and that adverse effects consist mainly of benign gastrointestinal complaints occurring in less than $5 \%$ of cases [34]. Our findings suggest a similar safe profile for NJ with a high percentage [>80\%] adhering to and completing the study protocol. The most commonly reported complaint was of its unpleasant taste and no one reported any rashes or allergic reactions. The issue of whether NJ causes hepatotoxicity is debated in the literatures [35-40]. However, in this pilot intervention study no evidence of liver toxicity was seen either clinically or in lab testing.

Hyperkalemia associated with NJ has also been reported previously [41], and one individual enrolled in the intervention study reported asymptomatic hyperkalemia and was dropped from the intervention study. Subsequent retesting revealed that the potassium level returned to normal after one week. The potassium content in NJ is consistent with many commonly consumed fruit juices and is significantly less than the amount found in higher potassium foods such as bananas. However, our experience and the published case reports of hyperkalemia associated with $\mathrm{NJ}$ suggests that NJ should be used cautiously in patients at risk for hyperkalemia and that serum potassium may need to be monitored in individuals using $\mathrm{NJ}$ on a consistent basis.

There are several important limitations to this study. First, the study was not a randomized trial with a control group and enrolled only a relatively small number of subjects. However, the study was not intended to be a definitive study but instead was planned as an exploratory pilot intervention study to see if $\mathrm{NJ}$ merited further investigation. The study findings appear sufficient to suggest that NJ may be a promising alternative to traditional treatment for $\mathrm{OA}$, meriting further investigation.

A second limitation was that only English speaking patients who had knee or hip pain attributed to OA by their family physician were included in the study. Third, only people over 40 years of age were included. By excluding younger and non-English speaking patients, our findings cannot be generalized to a broad spectrum of patients or those with other types of musculoskeletal symptoms. Fourth, since significantly fewer men than women enrolled in the intervention study, generalizing the findings to men should be done with caution. Fifth, we chose not to use the diagnostic criteria of the American College of Rheumatology for OA of the hip and knee, relying instead on confirmation from x-ray examination provided by a primary care physician that the person enrolling in the study had OA. We believe, however, that our inclusion criteria were more consistent with how $\mathrm{NJ}$ is used and were appropriate for a pilot intervention 
study. A sixth limitation centers on patients who were lost to follow up. We recognize that it is possible that some of those individuals might have experienced side effects. However, we believe it unlikely that any unreported side-effects represent a serious adverse reaction. Throughout the intervention study, the coordinator requested that anyone experiencing problems contact her and no one other than the individual with asymptomatic hyperkalemia did so. In several attempts to contact those who dropped out, no one responded with a concern related to NJ. Finally NJ [Tahitain Noni ${ }^{\circledR}$ juice] the product used in this intervention study may be unique and other noni products may not yield similar benefit. Another limitation is that the findings rely primarily on self-reported data and as such is subject to bias especially in an open label trial. However, this study used validated reporting scales and in a disease such as OA where the goal is to improve symptoms self report is a key marker for determining the efficacy of a treatment. While open label, the authors believe the strength of the findings coupled with its relative safety suggest that NJ merits further investigation in a blinded study.

\section{Conclusion}

The results from this 12 -week pilot intervention study suggest that NJ is potential, safe, and effective agent that may be able to reduce the symptoms of OA and help improve QoL. While other studies have demonstrated the pharmacologic effects of NJ in vitro and in animal models, few human studies have been conducted to support NJ benefits in a clinical setting. This pilot study suggests the need for further rigorous examination to confirm the benefits seen here and to ascertain the safety profile of $\mathrm{NJ}$ in a larger sample.

\section{List of abbreviations:}

$\mathrm{NJ}=$ Noni juice; QoL=Quality of Life; OA=Osteoarthritis; BMI=Body Mass Index; AIMS 2=Arthritis Impact Measurement Scales; SF-36 V2=Short Form-36 Version 2; NSAIDs=Nonsteroid anti-inflammatory drugs; hsCRP=High Sensitive C Reactive Protein; ROS=Reactive Oxygen Species; LPO=lipid peroxides; GI= Gastrointestinal; Cox=Cyclooxy-genase; SD rats=Sprague Dawley rats; GABAa=gamma-aminobutyric acid A; ALP=alkaline phosphatase; $\mathrm{AST}=$ Aspartate aminotransferase; ALT=Alanine aminotransferase; OTC $=$ Over-the-counter; LPS=Lipopolysaccharides.

\section{Competing interests}

Dr. Wang ever received other research grants from Morinda Holding Inc.

\section{Authors' Contributions}

Mian-Ying Wang, MD, MS is the principle investigator for this study providing oversight and contributed fundamental conceptualization for the research, writing a grant proposal and manuscript. 
M. Nawal Lutfiyya, $\mathrm{PhD}$ is a chronic disease epidemiologist and provided statistical analysis and assisted in writing the manuscript.

Vicki Weidenbacher-Hoper, MSW is the research coordinator for the study.

Lin Peng, MD performed all of the lab work for the study.

Martin S. Lipsky, MD, MS contributed to the conceptualization of the research protocol and assisted in writing the manuscript.

Gary Anderson, MD contributed to the conceptualization of the research protocol and assisted in writing the manuscript.

\section{Acknowledgements}

This study was supported by a State of Illinois Excellence in Academic Medicine Grant. We thank Morinda Holding Inc. for the donation of Tahitian Noni® juice for this clinical intervention. We gratefully acknowledge the comments and suggestions offered by Eric Henley, $\mathrm{MD}, \mathrm{MPH}$.

\section{References}

1. Hunter DJ, Eckstein F. Exercise and osteoarthritis. J Anat. 2009;214:197-207.

2. Bedson J, Mottram S, Thomas E, Peat G. Knee pain and osteoarthritis in the general population: what influences patients to consult? Fam Pract. 2007; 24:443-53.

3. Weigl M, Cieza A, Cantista P, Reinhardt JD, Stucki G. Determinants of disability in chronic musculoskeletal health conditions: a literature review. Eur J Phys Rehabil Med. 2008;1:67-79.

4. Myers SL, Flusser D, Brandt KD, Heck DA. Prevalence of cartilage shards in synovium and their association with synovitis in patients with early and endstage osteoarthritis. J Rheumatol. 1992; 8:1247-51.

5. Krasnokutsky S, Samuels J, Abramson SB. Osteoarthritis in 2007. Bull NYU Hosp Jt Dis. 2007; 65:222-8.

6. Pearson-Ceol J. Literature review on the effects of obesity on knee osteoarthritis. Orthop Nurs. 2007;26:289-92.

7. Dieppe P, Brandt KD. What is important in treating osteoarthritis? Whom should we treat and how should we treat them? Rheum Dis Clin North Am. 2003;29:687-716.

8. Read SJ, Dray A. Osteoarthritic pain: a review of current, theoretical and emerging therapeutics. Expert Opin Investig Drugs. 2008;17:619-40.

9. P Sooriakumaran. COX - 2 inhibitors and the heart: are all coxibs the same? Postgrad Med J. 2006; 82: 242-245.

10. Hogenmiller MS, Lozada CJ. An update on osteoarthritis therapeutics. Curr Opin Rheumatol. 2006;18:256-60.

11. Sooriakumaran P. COX-2 inhibitors and the heart: are all coxibs the same? Postgrad Med J. 2006;82:242-245. 
12. Potterat O, Hamburger M. Morinda citrifolia (Noni) fruit--phytochemistry, pharmacology, safety. Planta Med. 2007;73:191-199.

13. Li RW, Myers SP, Leach DN, Lin GD, Leach G. A cross-cultural study: antiinflammatory activity of Australian and Chinese plants. J Ethnopharmacol. 2003;85:2532.

14. Pawlus AD, Kinghorn DA. Review of the ethnobotany, chemistry, biological activity and safety of the botanical dietary supplement Morinda citrifolia [Noni]. J Pharm Pharmacol. 2007;59:1587-609.

15. McClatchey W. From Polynesian healers to health food stores: changing perspectives of Morinda citrifolia [Rubiaceae]. Integr Cancer Ther. 2002;1:110-120.

16. McKoy ML, Thomas EA, Simon OR. Preliminary investigation of the anti-inflammatory properties of an aqueous extract from Morinda citrifolia (noni). Proc West Pharmacol Soc. 2002;45:76-8.

17. Basar S, Uhlenhut K, Högger P, Schöne F, Westendorf J. Analgesic and antiinflammatory activity of Morinda citrifolia L. (Noni) fruit. Phytother Res. 2010;24:38-42.

18. Younos C, Rolland A, Fleurentin J, Lanhers MC, Miss lin R, Mortier F. Analgesic and behavioural effects of Morinda citrifolia. Planta Med 1990; 56: 430-434.

19. Wang MY, West BJ, Jensen CJ, Nowicki D, Su C, Palu AK, Anderson G. Morinda citrifolia (Noni): a literature review and recent advances in Noni research. Acta Pharmacol Sin. 2002;23:1127-1141.

20. Wang MY, Nowicki D, Anderson G, Jensen J, West B. Liver Protective Effects of Morinda citrifolia (Noni). Plant Foods Hum Nutr. 2008;63:59-63.

21. Wang MY, Lutfiyya MN, Weidenbacher-Hoper V, Anderson G, Su CX, West BJ. Antioxidant activity of noni juice in heavy smokers. Chem Cent J. 2009;3:13.

22. Deng S, Palu K, West BJ, Su CX, Zhou BN, Jensen JC. Lipoxygenase inhibitory constituents of the fruits of noni [Morinda citrifolia] collected in Tahiti. J Nat Prod. 2007;70:859-62.

23. Dziedzic KS, Thomas E, Hay EM. A systematic search and critical review of measures of disability for use in a population survey of hand osteoarthritis [OA]. Osteoarthritis Cartilage. 2005;13:1-12.

24. 24. Kalman, DS, Heimer M, Valdeon A, Schwartz H, Sheldon E. Effect of a natural extract of chicken combs with a high content of hyaluronic acid [Hyal-Joint $\left.{ }^{\circledR}\right]$ on pain relief and quality of life in subjects with knee osteoarthritis: a pilot randomized doubleblind placebo-controlled trial. Nutr J. 2008; $7: 3$.

25. Schlenk EA, Erlen JA, Dunbar-Jacob J, McDowell J, Engberg S, Sereika SM, Rohay JM, Bernier MJ. Health-related quality of life in chronic disorders: a comparison across studies using the MOS SF-36. Qual Life Res. 1998;7:57-65. 
26. Xiong T, Daniels J, Middleton L, Champaneria R, Khan KS, Gray R, Johnson N, Lichten EM, Sutton C, Jones KD, Chen FP, Vercellini P, Aimi G, Lui WM; International LUNA IPD Meta-analysis Collaborative Group. Meta-analysis using individual patient data from randomised trials to assess the effectiveness of laparoscopic uterosacral nerve ablation in the treatment of chronic pelvic pain: a proposed protocol. BJOG. 2007; 114:1580, e1-7.

27. Moran JL, Solomon PJ. Statistics in review Part I: graphics, data summary and linear models. Crit Care Resusc. 2007;9:81-90.

28. Marsh J, Hager C, Havey T, Sprague S, Bhandari M, Bryant D. Use of Alternative Medicines by Patients with OA that Adversely Interact with Commonly Prescribed Medications. Clin Orthop Relat Res. 2009;467:2705-2722

29. Kusirisin W, Srichairatanakool S, Lerttrakarnnon P, Lailerd N, Suttajit M, Jaikang C, et al. Antioxidative activity, polyphenolic content and anti-glycation effect of some Thai medicinal plants traditionally used in diabetic patients. Med Chem. 2009;5:139-47.

30. Xiang W, Song QS, Zhang HJ, Guo SP. Antimicrobial anthraquinones from Morinda angustifolia. Fitoterapia. 2008;79:501-4.

31. Palu A, Deng S, West B, Jensen J. Xanthine oxidase inhibiting effects of noni (Morinda citrifolia) fruit juice. Phytother Res. 2009;23:1790-1.

32. Pak-Dek MS, Abdul-Hamid A, Osman A, Soh CS. Inhibitory effect of morinda citrifolia L. On lipoprotein lipase activity. J Food Sci. 2008;73:C595-8.

33. Akinbo SRA, Noronha CC, Okanlawon AO, Denesi MA. Comparative study of the effect of Morinda citrifolia [Noni] with selected physiotherapy modalities in the management of patients with cervical spondylosis. Nigerian Journal of Health and Biomedical Sciences. 2006; 5: 6-11.

34. Potterat O, Hamburger M. Morinda citrifolia [Noni] fruit--phytochemistry, pharmacology, safety. Planta Med. 2007;73:191-199.

35. Stadlbauer V, Fickert P, Lackner C, Schmerlaib J, Krisper P, Trauner M, Stauber RE. Hepatotoxicity of NONI juice: report of two cases. World J Gastroenterol. 2005;11:475860.

36. Yuce B, Gulberg V, Diebold J, Gerbes AL. Hepatitis induced by Noni juice from Morinda citrifolia: a rare cause of hepatotoxicity or the tip of the iceberg? Digestion. 2006;73:167-70.

37. Wang MY, Nowicki D, Anderson G, Jensen J, West B. Liver protective effects of Morinda citrifolia [Noni]. Plant Foods Hum Nutr. 2008 Jun;63[2]:59-63.

38. West BJ, Jensen CJ, Westendorf J. Noni juice is not hepatotoxic. World J Gastroenterol. 2006;12:3616-9.

39. Wang MY, Anderson G, Nowicki D, Jensen J. Hepatic protection by noni fruit juice against $\mathrm{CCl}_{4}$-induced chronic liver damage in female SD rats. Plant Foods Hum Nutr. 2008; 63: 141-5. 
40. Wang MY, Li GD, Su C, Peng L, Anderson G, Jensen J. Iridoids from Morinda citrifolia [noni] show strong antioxidant activity and protect hepatocyte ultrastrure in acute liver injury. The proceeding of the First World Conference of Noni Research. P365-380. October 1, 2010.

41. Mueller BA, Scott MK, Sowinski KM, Prag KA. Noni juice [Morinda citrifolia]: hidden potential for hyperkalemia? Am J Kidney Dis. 2000;35:310-2. 